Dilemmas in a General Theory of Planning

Author(s): Horst W. J. Rittel and Melvin M. Webber

Source: Policy Sciences, Vol. 4, No. 2 (Jun., 1973), pp. 155-169

Published by: Springer

Stable URL: http://www.jstor.org/stable/4531523

Accessed: 09/02/2011 17:34

Your use of the JSTOR archive indicates your acceptance of JSTOR's Terms and Conditions of Use, available at http://www.jstor.org/page/info/about/policies/terms.jsp. JSTOR's Terms and Conditions of Use provides, in part, that unless you have obtained prior permission, you may not download an entire issue of a journal or multiple copies of articles, and you may use content in the JSTOR archive only for your personal, non-commercial use.

Please contact the publisher regarding any further use of this work. Publisher contact information may be obtained at http://www.jstor.org/action/showPublisher?publisherCode=springer.

Each copy of any part of a JSTOR transmission must contain the same copyright notice that appears on the screen or printed page of such transmission.

JSTOR is a not-for-profit service that helps scholars, researchers, and students discover, use, and build upon a wide range of content in a trusted digital archive. We use information technology and tools to increase productivity and facilitate new forms of scholarship. For more information about JSTOR, please contact support@jstor.org. 


\title{
Dilemmas in a General Theory of Planning*
}

\author{
HORST W. J. RITTEL \\ Professor of the Science of Design, University of California, Berkeley \\ MELVIN M. WEBBER \\ Professor of City Planning, University of California, Berkeley
}

\begin{abstract}
The search for scientific bases for confronting problems of social policy is bound to fail, because of the nature of these problems. They are "wicked" problems, whereas science has developed to deal with "tame" problems. Policy problems cannot be definitively described. Moreover, in a pluralistic society there is nothing like the undisputable public good; there is no objective definition of equity; policies that respond to social problems cannot be meaningfully correct or false; and it makes no sense to talk about "optimal solutions" to social problems unless severe qualifications are imposed first. Even worse, there are no "solutions" in the sense of definitive and objective answers.
\end{abstract}

George Bernard Shaw diagnosed the case several years ago; in more recent times popular protest may have already become a social movement. Shaw averred that "every profession is a conspiracy against the laity." The contemporary publics are responding as though they have made the same discovery.

Few of the modern professionals seem to be immune from the popular attackwhether they be social workers, educators, housers, public health officials, policemen, city planners, highway engineers or physicians. Our restive clients have been telling us that they don't like the educational programs that schoolmen have been offering, the redevelopment projects urban renewal agencies have been proposing, the lawenforcement styles of the police, the administrative behavior of the welfare agencies, the locations of the highways, and so on. In the courts, the streets, and the political campaigns, we've been hearing ever-louder public protests against the professions' diagnoses of the clients' problems, against professionally designed governmental programs, against professionally certified standards for the public services.

It does seem odd that this attack should be coming just when professionals in

* This is a modification of a paper presented to the Panel on Policy Sciences, American Association for the Advancement of Science, Boston, December 1969. 
the social services are beginning to acquire professional competencies. It might seem that our publics are being perverse, having condoned professionalism when it was really only dressed-up amateurism and condemning professionalism when we finally seem to be getting good at our jobs. Perverse though the laity may be, surely the professionals themselves have been behind this attack as well.

Some of the generators of the confrontation have been intellectual in origin. The anti-professional movement stems in part from a reconceptualization of the professional's task. Others are more in the character of historical imperatives, i.e. conditions have been thrown up by the course of societal events that call for different modes of intervention.

The professional's job was once seen as solving an assortment of problems that appeared to be definable, understandable and consensual. He was hired to eliminate those conditions that predominant opinion judged undesirable. His record has been quite spectacular, of course; the contemporary city and contemporary urban society stand as clean evidences of professional prowess. The streets have been paved, and roads now connect all places; houses shelter virtually everyone; the dread diseases are virtually gone; clean water is piped into nearly every building; sanitary sewers carry wastes from them; schools and hospitals serve virtually every district; and so on. The accomplishments of the past century in these respects have been truly phenomenal, however short of some persons' aspirations they might have been.

But now that these relatively easy problems have been dealt with, we have been turning our attention to others that are much more stubborn. The tests for efficiency, that were once so useful as measures of accomplishment, are being challenged by a renewed preoccupation with consequences for equity. The seeming consensus, that might once have allowed distributional problems to be dealt with, is being eroded by the growing awareness of the nation's pluralism and of the differentiation of values that accompanies differentiation of publics. The professionalized cognitive and occupational styles that were refined in the first half of this century, based in Newtonian mechanistic physics, are not readily adapted to contemporary conceptions of interacting open systems and to contemporary concerns with equity. A growing sensitivity to the waves of repercussions that ripple through such systemic networks and to the value consequences of those repercussions has generated the recent reexamination of received values and the recent search for national goals. There seems to be a growing realization that a weak strut in the professional's support system lies at the juncture where goal-formulation, problem-definition and equity issues meet. We should like to address these matters in turn.

\section{Goal Formulation}

The search for explicit goals was initiated in force with the opening of the 1960s. In a 1960 RAND publication, Charles J. Hitch urged that "We must learn to look at our objectives as critically and as professionally as we look at our models and our other inputs." 1 The subsequent work in systems analysis reaffirmed that injunction.

1 Charles J. Hitch, "On the Choice of Objectives in Systems Studies" (Santa Monica, California: The RAND Corporation, 1960; P-1955), p. 19. 
Men in a wide array of fields were prompted to redefine the systems they dealt with in the syntax of verbs rather than nouns-to ask "What do the systems do?" rather than "What are they made of?"- -and then to ask the most difficult question of all: "What should these systems do?" Also 1960 was inaugurated with the publication of Goals for Americans, the report of President Eisenhower's Commission on National Goals. ${ }^{2}$ There followed then a wave of similar efforts. The Committee for Economic Development commissioned a follow-up re-examination. So did the Brookings Institution, the American Academy of Arts and Sciences, and then President Nixon through his National Goals Research Staff. But these may be only the most apparent attempts to clarify the nation's directions. ${ }^{3}$

Perhaps more symptomatic in the U.S. were the efforts to install PPBS, which requires explication of desired outcomes; and then the more recent attempts to build systems of social indicators, which are in effect surrogates for statements of desired conditions. As we all now know, it has turned out to be terribly difficult, if not impossible, to make either of these systems operational. Although there are some small success stories recounted in a few civilian agencies, successes are still rare. Goal-finding is turning out to be an extraordinarily obstinate task. Because goal-finding is one of the central functions of planning, we shall shortly want to ask why that must be so.

At the same time that these formalized attempts were being made to discover our latent aims, the nation was buffeted by the revolt of the blacks, then by the revolt of the students, then by the widespread revolt against the war, more recently with a new consumerism and conservationism. All these movements were striking out at the underlying systemic processes of contemporary American society. In a style rather different from those of the systems analysts and the Presidential commissioners, participants in these revolts were seeking to restructure the value and goal systems that affect the distribution of social product and shape the directions of national policy.

Systems analysis, goals commissions, PPBS, social indicators, the several revolts, the poverty program, model cities, the current concerns with environmental quality and with the qualities of urban life, the search for new religions among contemporary youth, and the increasing attractiveness of the planning idea-all seem to be driven by a common quest. Each in its peculiar way is asking for a clarification of purposes, for a redefinition of problems, for a re-ordering of priorities to match stated purposes, for the design of new kinds of goal-directed actions, for a reorientation of the professions to the outputs of professional activities rather than to the inputs into them, and then for a redistribution of the outputs of governmental programs among the competing publics.

A deep-running current of optimism in American thought seems to have been propelling these diverse searches for direction-finding instruments. But at the same time, the Americans' traditional faith in a guaranteed Progress is being eroded by the same waves that are wearing down old beliefs in the social order's inherent goodness and in history's intrinsic benevolence. Candide is dead. His place is being

2 The report was published by Spectrum Books, Prentice-Hall, 1960.

${ }^{3}$ At the same time to be sure, counter voices-uncomfortable to many-were claiming that the "nation's direction" presents no meaningful reference system at all, owing to the worldwide character of the problems and the overspill of crises across national boundaries. 
occupied by a new conception of future history that, rejecting historicism, is searching for ways of exploiting the intellectual and inventive capabilities of men.

This belief comes in two quite contradictory forms. On the one hand, there is the belief in the "makeability," or unrestricted malleability, of future history by means of the planning intellect-by reasoning, rational discourse, and civilized negotiation. At the same time, there are vocal proponents of the "feeling approach," of compassionate engagement and dramatic action, even of a revival of mysticism, aiming at overcoming The System which is seen as the evil source of misery and suffering.

The Enlightenment may be coming to full maturity in the late 20th century, or it may be on its deathbed. Many Americans seem to believe both that we can perfect future history - that we can deliberately shape future outcomes to accord with our wishes - and that there will be no future history. Some have arrived at deep pessimism and some at resignation. To them, planning for large social systems has proved to be impossible without loss of liberty and equity. Hence, for them the ultimate goal of planning should be anarchy, because it should aim at the elimination of government over others. Still another group has arrived at the conclusion that liberty and equity are luxuries which cannot be afforded by a modern society, and that they should be substituted by "cybernetically feasible" values.

Professionalism has been understood to be one of the major instruments for perfectability, an agent sustaining the traditional American optimism. Based in modern science, each of the professions has been conceived as the medium through which the knowledge of science is applied. In effect, each profession has been seen as a subset of engineering. Planning and the emerging policy sciences are among the more optimistic of those professions. Their representatives refuse to believe that planning for betterment is impossible, however grave their misgivings about the appropriateness of past and present modes of planning. They have not abandoned the hope that the instruments of perfectability can be perfected. It is that view that we want to examine, in an effort to ask whether the social professions are equipped to do what they are expected to do.

\section{Problem Definition}

During the industrial age, the idea of planning, in common with the idea of professionalism, was dominated by the pervasive idea of efficiency. Drawn from 18th century physics, classical economics and the principle of least-means, efficiency was seen as a condition in which a specified task could be performed with low inputs of resources. That has been a powerful idea. It has long been the guiding concept of civil engineering, the scientific management movement, much of contemporary operations research; and it still pervades modern government and industry. When attached to the idea of planning, it became dominating there too. Planning was then seen as a process of designing problem-solutions that might be installed and operated cheaply. Because it was fairly easy to get consensus on the nature of problems during the early industrial period, the task could be assigned to the technically skilled, who in turn could be trusted to accomplish the simplified end-in-view. Or, in the more work-a-day setting, we could rely upon the efficiency expert to diagnose a problem 
and then solve it, while simultaneously reducing the resource inputs into whatever it was we were doing.

We have come to think about the planning task in very different ways in recent years. We have been learning to ask whether what we are doing is the right thing to do. That is to say, we have been learning to ask questions about the outputs of actions and to pose problem statements in valuative frameworks. We have been learning to see social processes as the links tying open systems into large and interconnected networks of systems, such that outputs from one become inputs to others. In that structural framework it has become less apparent where problem centers lie, and less apparent where and how we should intervene even if we do happen to know what aims we seek. We are now sensitized to the waves of repercussions generated by a problem-solving action directed to any one node in the network, and we are no longer surprised to find it inducing problems of greater severity at some other node. And so we have been forced to expand the boundaries of the systems we deal with, trying to internalize those externalities.

This was the professional style of the systems analysts, who were commonly seen as forebearers of the universal problem-solvers. With arrogant confidence, the early systems analysts pronounced themselves ready to take on anyone's perceived problem, diagnostically to discover its hidden character, and then, having exposed its true nature, skillfully to excise its root causes. Two decades of experience have worn the self-assurances thin. These analysts are coming to realize how valid their model really is, for they themselves have been caught by the very same diagnostic difficulties that troubled their clients.

By now we are all beginning to realize that one of the most intractable problems is that of defining problems (of knowing what distinguishes an observed condition from a desired condition) and of locating problems (finding where in the complex causal networks the trouble really lies). In turn, and equally intractable, is the problem of identifying the actions that might effectively narrow the gap between what-is and what-ought-to-be. As we seek to improve the effectiveness of actions in pursuit of valued outcomes, as system boundaries get stretched, and as we become more sophisticated about the complex workings of open societal systems, it becomes ever more difficult to make the planning idea operational.

Many now have an image of how an idealized planning system would function. It is being seen as an on-going, cybernetic process of governance, incorporating systematic procedures for continuously searching out goals; identifying problems; forecasting uncontrollable contextual changes; inventing alternative strategies, tactics, and timesequenced actions; stimulating alternative and plausible action sets and their consequences; evaluating alternatively forecasted outcomes; statistically monitoring those conditions of the publics and of systems that are judged to be germane; feeding back information to the simulation and decision channels so that errors can be corrected-all in a simultaneously functioning governing process. That set of steps is familiar to all of us, for it comprises what is by now the modern-classical model of planning. And yet we all know that such a planning system is unattainable, even as we seek more closely to approximate it. It is even questionable whether such a planning system is desirable. 


\section{Planning Problems are Wicked Problems}

A great many barriers keep us from perfecting such a planning/governing system: theory is inadequate for decent forecasting; our intelligence is insufficient to our tasks; plurality of objectives held by pluralities of politics makes it impossible to pursue unitary aims; and so on. The difficulties attached to rationality are tenacious, and we have so far been unable to get untangled from their web. This is partly because the classical paradigm of science and engineering - the paradigm that has underlain modern professionalism -is not applicable to the problems of open societal systems. One reason the publics have been attacking the social professions, we believe, is that the cognitive and occupational styles of the professions-mimicking the cognitive style of science and the occupational style of engineering - have just not worked on a wide array of social problems. The lay customers are complaining because planners and other professionals have not succeeded in solving the problems they claimed they could solve. We shall want to suggest that the social professions were misled somewhere along the line into assuming they could be applied scientiststhat they could solve problems in the ways scientists can solve their sorts of problems. The error has been a serious one.

The kinds of problems that planners deal with-societal problems-are inherently different from the problems that scientists and perhaps some classes of engineers deal with. Planning problems are inherently wicked.

As distinguished from problems in the natural sciences, which are definable and separable and may have solutions that are findable, the problems of governmental planning - and especially those of social or policy planning-are ill-defined; and they rely upon elusive political judgment for resolution. (Not "solution." Social problems are never solved. At best they are only re-solved-over and over again.) Permit us to draw a cartoon that will help clarify the distinction we intend.

The problems that scientists and engineers have usually focused upon are mostly "tame" or "benign" ones. As an example, consider a problem of mathematics, such as solving an equation; or the task of an organic chemist in analyzing the structure of some unknown compound; or that of the chessplayer attempting to accomplish checkmate in five moves. For each the mission is clear. It is clear, in turn, whether or not the problems have been solved.

Wicked problems, in contrast, have neither of these clarifying traits; and they include nearly all public policy issues-whether the question concerns the location of a freeway, the adjustment of a tax rate, the modification of school curricula, or the confrontation of crime.

There are at least ten distinguishing properties of planning-type problems, i.e. wicked ones, that planners had better be alert to and which we shall comment upon in turn. As you will see, we are calling them "wicked" not because these properties are themselves ethically deplorable. We use the term "wicked" in a meaning akin to that of "malignant" (in contrast to "benign") or "vicious" (like a circle) or "tricky" (like a leprechaun) or "aggressive" (like a lion, in contrast to the docility of a lamb). We do not mean to personify these properties of social systems by implying malicious 
intent. But then, you may agree that it becomes morally objectionable for the planner to treat a wicked problem as though it were a tame one, or to tame a wicked problem prematurely, or to refuse to recognize the inherent wickedness of social problems.

\section{There is no definitive formulation of a wicked problem}

For any given tame problem, an exhaustive formulation can be stated containing all the information the problem-solver needs for understanding and solving the problem -provided he knows his "art," of course.

This is not possible with wicked-problems. The information needed to understand the problem depends upon one's idea for solving it. That is to say: in order to describe a wicked-problem in sufficient detail, one has to develop an exhaustive inventory of all conceivable solutions ahead of time. The reason is that every question asking for additional information depends upon the understanding of the problem-and its resolution-at that time. Problem understanding and problem resolution are concomitant to each other. Therefore, in order to anticipate all questions (in order to anticipate all information required for resolution ahead of time), knowledge of all conceivable solutions is required.

Consider, for example, what would be necessary in identifying the nature of the poverty problem. Does poverty mean low income? Yes, in part. But what are the determinants of low income? Is it deficiency of the national and regional economies, or is it deficiencies of cognitive and occupational skills within the labor force? If the latter, the problem statement and the problem "solution" must encompass the educational processes. But, then, where within the educational system does the real problem lie? What then might it mean to "improve the educational system"? Or does the poverty problem reside in deficient physical and mental health? If so, we must add those etiologies to our information package, and search inside the health services for a plausible cause. Does it include cultural deprivation? spatial dislocation? problems of ego identity? deficient political and social skills?-and so on. If we can formulate the problem by tracing it to some sorts of sources-such that we can say, "Aha! That's the locus of the difficulty," i.e. those are the root causes of the differences between the "is" and the "ought to be" conditions-then we have thereby also formulated a solution. To find the problem is thus the same thing as finding the solution; the problem can't be defined until the solution has been found.

The formulation of a wicked problem is the problem! The process of formulating the problem and of conceiving a solution (or re-solution) are identical, since every specification of the problem is a specification of the direction in which a treatment is considered. Thus, if we recognize deficient mental health services as part of the problem, then-trivially enough-"improvement of mental health services" is a specification of solution. If, as the next step, we declare the lack of community centers one deficiency of the mental health services system, then "procurement of community centers" is the next specification of solution. If it is inadequate treatment within community centers, then improved therapy training of staff may be the locus of solution, and so on.

This property sheds some light on the usefulness of the famed "systems-approach" 
for treating wicked problems. The classical systems-approach of the military and the space programs is based on the assumption that a planning project can be organized into distinct phases. Every textbook of systems engineering starts with an enumeration of these phases: "understand the problems or the mission," "gather information," "analyze information," "synthesize information and wait for the creative leap," "work out solution," or the like. For wicked problems, however, this type of scheme does not work. One cannot understand the problem without knowing about its context; one cannot meaningfully search for information without the orientation of a solution concept; one cannot first understand, then solve. The systems-approach "of the first generation" is inadequate for dealing with wicked-problems. Approaches of the "second generation" should be based on a model of planning as an argumentative process in the course of which an image of the problem and of the solution emerges gradually among the participants, as a product of incessant judgment, subjected to critical argument. The methods of Operations Research play a prominent role in the systems-approach of the first generation; they become operational, however, only after the most important decisions have already been made, i.e. after the problem has already been tamed.

Take an optimization model. Here the inputs needed include the definition of the solution space, the system of constraints, and the performance measure as a function of the planning and contextual variables. But setting up and constraining the solution space and constructing the measure of performance is the wicked part of the problem. Very likely it is more essential than the remaining steps of searching for a solution which is optimal relative to the measure of performance and the constraint system.

\section{Wicked problems have no stopping rule}

In solving a chess problem or a mathematical equation, the problem-solver knows when he has done his job. There are criteria that tell when the or $a$ solution has been found.

Not so with planning problems. Because (according to Proposition 1) the process of solving the problem is identical with the process of understanding its nature, because there are no criteria for sufficient understanding and because there are no ends to the causal chains that link interacting open systems, the would-be planner can always try to do better. Some additional investment of effort might increase the chances of finding a better solution.

The planner terminates work on a wicked problem, not for reasons inherent in the "logic" of the problem. He stops for considerations that are external to the problem: he runs out of time, or money, or patience. He finally says, "That's good enough," or "This is the best I can do within the limitations of the project," or "I like this solution," etc.

\section{Solutions to wicked problems are not true-or-false, but good-or-bad}

There are conventionalized criteria for objectively deciding whether the offered solution to an equation or whether the proposed structural formula of a chemical compound is correct or false. They can be independently checked by other qualified 
persons who are familiar with the established criteria; and the answer will be normally unambiguous.

For wicked planning problems, there are no true or false answers. Normally, many parties are equally equipped, interested, and/or entitled to judge the solutions, although none has the power to set formal decision rules to determine correctness. Their judgments are likely to differ widely to accord with their group or personal interests, their special value-sets, and their ideological predilections. Their assessments of proposed solutions are expressed as "good" or "bad" or, more likely, as "better or worse" or "satisfying" or "good enough."

\section{There is no immediate and no ultimate test of a solution to a wicked problem}

For tame-problems one can determine on the spot how good a solution-attempt has been. More accurately, the test of a solution is entirely under the control of the few people who are involved and interested in the problem.

With wicked problems, on the other hand, any solution, after being implemented, will generate waves of consequences over an extended-virtually an unboundedperiod of time. Moreover, the next day's consequences of the solution may yield utterly undesirable repercussions which outweigh the intended advantages or the advantages accomplished hitherto. In such cases, one would have been better off if the plan had never been carried out.

The full consequences cannot be appraised until the waves of repercussions have completely run out, and we have no way of tracing all the waves through all the affected lives ahead of time or within a limited time span.

\section{Every solution to a wicked problem is a "one-shot operation"; because there is no opportunity to learn by trial-and-error, every attempt counts significantly}

In the sciences and in fields like mathematics, chess, puzzle-solving or mechanical engineering design, the problem-solver can try various runs without penalty. Whatever his outcome on these individual experimental runs, it doesn't matter much to the subject-system or to the course of societal affairs. A lost chess game is seldom consequential for other chess games or for non-chess-players.

With wicked planning problems, however, every implemented solution is consequential. It leaves "traces" that cannot be undone. One cannot build a freeway to see how it works, and then easily correct it after unsatisfactory performance. Large public-works are effectively irreversible, and the consequences they generate have long half-lives. Many people's lives will have been irreversibly influenced, and large amounts of money will have been spent-another irreversible act. The same happens, with most other large-scale public works and with virtually all public-service programs. The effects of an experimental curriculum will follow the pupils into their adult lives.

Whenever actions are effectively irreversible and whenever the half-lives of the consequences are long, every trial counts. And every attempt to reverse a decision or to correct for the undesired consequences poses another set of wicked problems, which are in turn subject to the same dilemmas. 


\section{Wicked problems do not have an enumerable (or an exhaustively describable) set of potential solutions, nor is there a well-described set of permissible operations that may be incorporated into the plan}

There are no criteria which enable one to prove that all solutions to a wicked problem have been identified and considered.

It may happen that no solution is found, owing to logical inconsistencies in the "picture" of the problem. (For example, the problem-solver may arrive at a problem description requiring that both $A$ and not- $A$ should happen at the same time.) Or it might result from his failing to develop an idea for solution (which does not mean that someone else might be more successful). But normally, in the pursuit of a wicked planning problem, a host of potential solutions arises; and another host is never thought up. It is then a matter of judgment whether one should try to enlarge the available set or not. And it is, of course, a matter of judgment which of these solutions should be pursued and implemented.

Chess has a finite set of rules, accounting for all situations that can occur. In mathematics, the tool chest of operations is also explicit; so, too, although less rigorously, in chemistry.

But not so in the world of social policy. Which strategies-or-moves are permissible in dealing with crime in the streets, for example, have been enumerated nowhere. "Anything goes," or at least, any new idea for a planning measure may become a serious candidate for a re-solution: What should we do to reduce street crime? Should we disarm the police, as they do in England, since even criminals are less likely to shoot unarmed men? Or repeal the laws that define crime, such as those that make marijuana use a criminal act or those that make car theft a criminal act? That would reduce crime by changing definitions. Try moral rearmament and substitute ethical self-control for police and court control? Shoot all criminals and thus reduce the numbers who commit crime? Give away free loot to would-be-thieves, and so reduce the incentive to crime? And so on.

In such fields of ill-defined problems and hence ill-definable solutions, the set of feasible plans of action relies on realistic judgment, the capability to appraise "exotic" ideas and on the amount of trust and credibility between planner and clientele that will lead to the conclusion, "OK let's try that."

\section{Every wicked problem is essentially unique}

Of course, for any two problems at least one distinguishing property can be found (just as any number of properties can be found which they share in common), and each of them is therefore unique in a trivial sense. But by "essentially unique" we mean that, despite long lists of similarities between a current problem and a previous one, there always might be an additional distinguishing property that is of overriding importance. Part of the art of dealing with wicked problems is the art of not knowing too early which type of solution to apply.

There are no classes of wicked problems in the sense that principles of solution can be developed to fit all members of a class. In mathematics there are rules for classifying families of problems-say, of solving a class of equations-whenever a 
certain, quite-well-specified set of characteristics matches the problem. There are explicit characteristics of tame problems that define similarities among them, in such fashion that the same set of techniques is likely to be effective on all of them.

Despite seeming similarities among wicked problems, one can never be certain that the particulars of a problem do not override its commonalities with other problems already dealt with.

The conditions in a city constructing a subway may look similar to the conditions in San Francisco, say; but planners would be ill-advised to transfer the San Francisco solutions directly. Differences in commuter habits or residential patterns may far outweigh similarities in subway layout, downtown layout and the rest. In the more complex world of social policy planning, every situation is likely to be one-of-a-kind. If we are right about that, the direct transference of the physical-science and engineering thoughtways into social policy might be dysfunctional, i.e. positively harmful. "Solutions" might be applied to seemingly familiar problems which are quite incompatible with them.

\section{Every wicked problem can be considered to be a symptom of another problem}

Problems can be described as discrepancies between the state of affairs as it is and the state as it ought to be. The process of resolving the problem starts with the search for causal explanation of the discrepancy. Removal of that cause poses another problem of which the original problem is a "symptom." In turn, it can be considered the symptom of still another, "higher level" problem. Thus "crime in the streets" can be considered as a symptom of general moral decay, or permissiveness, or deficient opportunity, or wealth, or poverty, or whatever causal explanation you happen to like best. The level at which a problem is settled depends upon the self-confidence of the analyst and cannot be decided on logical grounds. There is nothing like a natural level of a wicked problem. Of course, the higher the level of a problem's formulation, the broader and more general it becomes: and the more difficult it becomes to do something about it. On the other hand, one should not try to cure symptoms: and therefore one should try to settle the problem on as high a level as possible.

Here lies a difficulty with incrementalism, as well. This doctrine advertises a policy of small steps, in the hope of contributing systematically to overall improvement. If, however, the problem is attacked on too low a level (an increment), then success of resolution may result in making things worse, because it may become more difficult to deal with the higher problems. Marginal improvement does not guarantee overall improvement. For example, computerization of an administrative process may result in reduced cost, ease of operation, etc. But at the same time it becomes more difficult to incur structural changes in the organization, because technical perfection reinforces organizational patterns and normally increases the cost of change. The newly acquired power of the controllers of information may then deter later modifications of their roles.

Under these circumstances it is not surprising that the members of an organization tend to see the problems on a level below their own level. If you ask a police chief what the problems of the police are, he is likely to demand better hardware. 


\section{The existence of a discrepancy representing a wicked problem can be explained in numerous ways. The choice of explanation determines the nature of the problem's resolution}

"Crime in the streets" can be explained by not enough police, by too many criminals, by inadequate laws, too many police, cultural deprivation, deficient opportunity, too many guns, phrenologic aberrations, etc. Each of these offers a direction for attacking crime in the streets. Which one is right? There is no rule or procedure to determine the "correct" explanation or combination of them. The reason is that in dealing with wicked problems there are several more ways of refuting a hypothesis than there are permissible in the sciences.

The mode of dealing with conflicting evidence that is customary in science is as follows: "Under conditions $C$ and assuming the validity of hypothesis $H$, effect $E$ must occur. Now, given $C, E$ does not occur. Consequently $H$ is to be refuted." In the context of wicked problems, however, further modes are admissible: one can deny that the effect $E$ has not occurred, or one can explain the nonoccurrence of $E$ by intervening processes without having to abandon $H$. Here's an example: Assume that somebody chooses to explain crime in the streets by "not enough police." This is made the basis of a plan, and the size of the police force is increased. Assume further that in the subsequent years there is an increased number of arrests, but an increase of offenses at a rate slightly lower than the increase of GNP. Has the effect $E$ occurred? Has crime in the streets been reduced by increasing the police force? If the answer is no, several nonscientific explanations may be tried in order to rescue the hypothesis $H$ ("Increasing the police force reduces crime in the streets"): "If we had not increased the number of officers, the increase in crime would have been even greater;" "This case is an exception from rule $H$ because there was an irregular influx of criminal elements;" "Time is too short to feel the effects yet;" etc. But also the answer "Yes, $E$ has occurred" can be defended: "The number of arrests was increased," etc.

In dealing with wicked problems, the modes of reasoning used in the argument are much richer than those permissible in the scientific discourse. Because of the essential uniqueness of the problem (see Proposition 7) and lacking opportunity for rigorous experimentation (see Proposition 5), it is not possible to put $H$ to a crucial test.

That is to say, the choice of explanation is arbitrary in the logical sense. In actuality, attitudinal criteria guide the choice. People choose those explanations which are most plausible to them. Somewhat but not much exaggerated, you might say that everybody picks that explanation of a discrepancy which fits his intentions best and which conforms to the action-prospects that are available to him. The analyst's "world view" is the strongest determining factor in explaining a discrepancy and, therefore, in resolving a wicked problem.

\section{The planner has no right to be wrong}

As Karl Popper argues in The Logic of Scientific Discovery, ${ }^{4}$ it is a principle of science that solutions to problems are only hypotheses offered for refutation. This

\footnotetext{
${ }^{4}$ Science Editions, New York, 1961.
} 
habit is based on the insight that there are no proofs to hypotheses, only potential refutations. The more a hypothesis withstands numerous attempts at refutation, the better its "corroboration" is considered to be. Consequently, the scientific community does not blame its members for postulating hypotheses that are later refuted-so long as the author abides by the rules of the game, of course.

In the world of planning and wicked problems no such immunity is tolerated. Here the aim is not to find the truth, but to improve some characteristics of the world where people live. Planners are liable for the consequences of the actions they generate; the effects can matter a great deal to those people that are touched by those actions.

We are thus led to conclude that the problems that planners must deal with are wicked and incorrigible ones, for they defy efforts to delineate their boundaries and to identify their causes, and thus to expose their problematic nature. The planner who works with open systems is caught up in the ambiguity of their causal webs. Moreover, his would-be solutions are confounded by a still further set of dilemmas posed by the growing pluralism of the contemporary publics, whose valuations of his proposals are judged against an array of different and contradicting scales. Let us turn to these dilemmas next.

\section{The Social Context}

There was a time during the 'Fifties when the quasi-sociological literature was predicting a Mass Society-foreseen as a rather homogeneously shared culture in which most persons would share values and beliefs, would hold to common aims, would follow similar life-styles, and thus would behave in similar ways. (You will recall the popular literature on suburbia of ten years ago.) It is now apparent that those forecasts were wrong.

Instead, the high-scale societies of the Western world are becoming increasingly heterogeneous. They are becoming increasingly differentiated, comprising thousands of minority groups, each joined around common interests, common value systems, and shared stylistic preferences that differ from those of other groups. As the sheer volume of information and knowledge increases, as technological developments further expand the range of options, and as awareness of the liberty to deviate and differentiate spreads, more variations are possible. Rising affluence or, even more, growing desire for at least subcultural identity induces groups to exploit those options and to invent new ones. We almost dare say that irregular cultural permutations are becoming the rule. We have come to realize that the melting pot never worked for large numbers of immigrants to America, ${ }^{5}$ and that the unitary conception of "The American Way of Life" is now giving way to a recognition that there are numerous ways of life that are also American.

It was pre-industrial society that was culturally homogeneous. The industrial age greatly expanded cultural diversity. Post-industrial society is likely to be far more differentiated than any in all of past history.

It is still too early to know whether the current politicization of subpublics is

\footnotetext{
${ }^{5}$ See an early sign of this growing realization in Nathan Glazer and Daniel Patrick Moynihan, Beyond the Melting Pot (Cambridge: Harvard and MIT Presses, 1963).
} 
going to be a long-run phenomenon or not. One could write scenarios that would be equally plausible either way. But one thing is clear: large population size will mean that small minorities can comprise large numbers of people; and, as we have been seeing, even small minorities can swing large political influence.

In a setting in which a plurality of publics is politically pursuing a diversity of goals, how is the larger society to deal with its wicked problems in a planful way? How are goals to be set, when the valuative bases are so diverse? Surely a unitary conception of $a$ unitary "public welfare" is an anachronistic one.

We do not even have a theory that tells us how to find out what might be considered a societally best state. We have no theory that tells us what distribution of the social product is best-whether those outputs are expressed in the coinage of money income, information income, cultural opportunities, or whatever. We have come to realize that the concept of the social product is not very meaningful; possibly there is no aggregate measure for the welfare of a highly diversified society, if this measure is claimed to be objective and non-partisan. Social science has simply been unable to uncover a social-welfare function that would suggest which decisions would contribute to a societally best state. Instead, we have had to rely upon the axioms of individualism that underlie economic and political theory, deducing, in effect, that the larger-public welfare derives from summation of individualistic choices. And yet, we know that this is not necessarily so, as our current experience with air pollution has dramatized.

We also know that many societal processes have the character of zero-sum games. As the population becomes increasingly pluralistic, inter-group differences are likely to be reflected as inter-group rivalries of the zero-sum sorts. If they do, the prospects for inventing positive non-zero-sum development strategies would become increasingly difficult.

Perhaps we can illustrate. A few years ago there was a nearly universal consensus in America that full-employment, high productivity, and widespread distribution of consumer durables fitted into a development strategy in which all would be winners. That consensus is now being eroded. Now, when substitutes for wages are being disbursed to the poor, the college student, and the retired, as well as to the more traditional recipient of nonwage incomes, our conceptions of "employment" and of a full-employment economy are having to be revised. Now, when it is recognized that raw materials that enter the economy end up as residuals polluting the air mantle and the rivers, many are becoming wary of rising manufacturing production. And, when some of the new middle-class religions are exorcising worldly goods in favor of less tangible communal "goods," the consumption-oriented society is being challenged--oddly enough, to be sure, by those who were reared in its affluence.

What was once a clear-cut win-win strategy, that had the status of a near-truism, has now become a source of contentious differences among subpublics.

Or, if these illustrations seem to be posed at too high a level of generality, consider the sorts of inter-group conflicts imbedded in urban renewal, roadway construction, or curriculum design in the public schools. Our observation is not only that values are changing. That is true enough, and the probabilities of parametric changes are large enough to humble even the most perceptive observer of contemporary norms. 
Our point, rather, is that diverse values are held by different groups of individualsthat what satisfies one may be abhorrent to another, that what comprises problemsolution for one is problem-generation for another. Under such circumstances, and in the absence of an overriding social theory or an overriding social ethic, there is no gainsaying which group is right and which should have its ends served.

One traditional approach to the reconciliation of social values and individual choice is to entrust de facto decision-making to the wise and knowledgeable professional experts and politicians. But whether one finds that ethically tolerable or not, we hope we have made it clear that even such a tactic only begs the question, for there are no value-free, true-false answers to any of the wicked problems governments must deal with. To substitute expert professional judgment for those of contending political groups may make the rationales and the repercussions more explicit, but it would not necessarily make the outcomes better. The one-best answer is possible with tame problems, but not with wicked ones.

Another traditional approach to the reconciliation of social values and individual choice is to bias in favor of the latter. Accordingly, one would promote widened differentiation of goods, services, environments, and opportunities, such that individuals might more closely satisfy their individual preferences. Where large-system problems are generated, he would seek to ameliorate the effects that he judges most deleterious. Where latent opportunities become visible, he would seek to exploit them. Where positive non-zero-sum developmental strategies can be designed, he would of course work hard to install them.

Whichever the tactic, though, it should be clear that the expert is also the player in a political game, seeking to promote his private vision of goodness over others'. Planning is a component of politics. There is no escaping that truism.

We are also suggesting that none of these tactics will answer the difficult questions attached to the sorts of wicked problems planners must deal with. We have neither a theory that can locate societal goodness, nor one that might dispel wickedness, nor one that might resolve the problems of equity that rising pluralism is provoking. We are inclined to think that these theoretic dilemmas may be the most wicked conditions that confront us. 